\section{A Typology of Production Control Situations in Process Industries}

Production

Control

Situations

Jan C. Fransoo

Eindhoven University of Technology, The N etherlands, and

Werner G.M.M. Rutten

Wageningen A gricultural U niversity, T he N etherlands

\section{Introduction}

During the last decade, various articles have appeared in professional and scientific journals regarding production control in process industries. The vast majority have focused on the typical characteristics of process industries production control vis-à-vis the more traditional approaches of production control for discrete manufacturing systems. In this body of literature, two schools of thought can be distinguished. The first advocates the applicability of traditional M RP (manufacturing requirements planning) concepts and systems in process industries[1-3]. The researchers and practitioners in this school concentrate on the specific characteristics that may occur in process industries and try to find solutions to be able to implement M RP. The second school stresses the differences between discrete and process manufacturers and comes with new or adapted techniques and concepts for production control in these situations[4]. Very seldom is the variety of production systems within process industries discussed. Some articles do address the problem of variety (or the opportunities this offers), but the consequences for production control are not worked out in more detail.

In this article, we will present a simple, though useful typology of process industries, which recognizes two extreme production systems on a continuum. The typology is in line with the A PICS (A merican Production and Inventory Control Society) definitions on process/flow and batch/mix[5]. A PICS defines batch/mix as:

A process business which primarily schedules short production runs of products.

Process/flow is defined as:

A manufacturer who produces with minimal interruptions in any one production run or between production runs of products which exhibit process characteristics such as liquids, fibres, powders, gases.

It will appear that these definitions are very useful in characterizing the manufacturing systems in view of the requirements for production control. M ost research so far has been focused on the process/flow systems; and what is

The authors are indebted to Professor J.W.M. B ertrand, whose suggestions considerably increased the quality of this article.
International Journal of Operations \& Production Management, $\mathrm{Vol} .14$ University Press, 0144-3577 No. 12, 1994, pp. 47-57. ๑ M CB 
IJOPM

14,12

being done on batch/mix systems mainly presents detailed scheduling/ programming approaches. A dditional research to obtain a production control framework for batch/mix businesses is therefore required.

A fter presenting the characteristics of process industries as recognized in the literature and organizing these characteristics for each of the two extremes, we will address the differences in production control in more detail. In the last section of the article we will draw some conclusions.

\section{Literature on Process Industries}

The general characteristics of process industries are well represented in the APICS definition:

Process industries are businesses that add value to materials by mixing, separating. forming, or chemical reactions. Processes may be either continuous or batch and generally require rigid process control and high capital investment[6].

The definition indicates that the type of manufacturing process performed is one of the most important characteristics. Mixing, separating, forming and chemical reactions are operations that are usually performed on non-discrete products and materials. These processes can only be performed efficiently using large installations, which tend to be very expensive. If large quantities are demanded, this justifies continuous production (thus higher investment). If demand is low, the investment into a large installation is not worthwhile, and batchwise production is used. A Iso, these processes are difficult to control which often results in typical symptoms as variable yield and returning flows of material.

In the literature, many characteristics are mentioned as being "typical" of process industries. Though these characteristics can be found in process industries, they are not general, in a sense that virtually all process industries are characterized by these issues. On the other hand, they are discriminating in that they will predominantly be found in process industries and not in discrete industries. In this section, we will provide an overview of these characteristics. Production scheduling in process industries is often complicated by a variable yield, due to the nature of the process, even if it is statistically under control[7]. In process/flow businesses, the yield can change as a function of processing decisions[8]. Burt and K raemer[9] present two ways to deal with variable yield in a production control system: (1) use a mean yield in the bill of materials (BOM) and (2) create a safety stock of raw materials which have the most variable yield. In a later paper however, Burt[10] states that variable yield should be controlled by creating safety time instead of safety stock.

Process industries often obtain their raw materials from mining or agricultural industries. These raw materials have natural variations in quality. For example, crude oils from different oil fields have different sulphur contents and different proportions of naphtha, distillates, and fuel oils. Oil refinery designs, production plans and operating schedules must account for this variability[4]. A nother aspect of materials variability associated with natural raw materials, is that the yield or potency is usually not known or measured 
until the process is started[11]. The variability in raw materials quality often determines which products will be produced[12]. Kochalka[1] advises to plan at the average quality or yield of the raw materials. If you get a different quality, it may mean reorder and recycle. This can result in shortages, but if the safety stocks are established giving consideration to the frequency of these occurrences, the stock-out impact can be minimized.

Variations in raw material quality often lead to variations in bills of material (recipes)[13]. For example, variations in the moisture contents, acidity, colour, viscosity or concentration of active ingredient in raw materials may cause variations in the ingredient proportions required to make finished product quality specifications[4]. A nother factor which causes variations in bills of material is the price of alternative ingredients[4]. For example, a pet food may have specifications for the minimum amount of proteins, carbohydrates and fats per pound of pet food; however, the proportions of various ingredients may be varied depending on their current price and availability. In process industries, inter mediate products are quality-measured and the results can dictate formula-sensitive processing steps requiring varying, not fixed, "quantities per..." and alternative or additive compounds. Seasonal considerations, the availability of raw materials, or even the unique vessel, tank or line availability can govern the best recipe (BOM) for production[14].

Process industries often initiate their flows with only a few raw materials and subsequently process a variety of blending and resplitting operations[14]. In other words, many products are produced from a few kinds of raw material, compared to the usual bill in discrete manufacturing in which end items contain many different components[12]. Figure 1 exhibits the differences between process and discrete manufacturers.

The divergence in the product flow sometimes is not voluntary because byproducts are being produced at certain processes[15]. It is important to structure the appropriate BOM to recognize the yield of by-products.T hese items in the BOM may be included by giving them a "negative quantity per", equal to the standard amount of the by-product yield[1,11]. When the requirements are exploded, these items will show as negative, or in other words, as an inventory gain. Duncan[2] developed a by-product BOM because the "negative quantity per" can cause "netting" being confused with "planning"

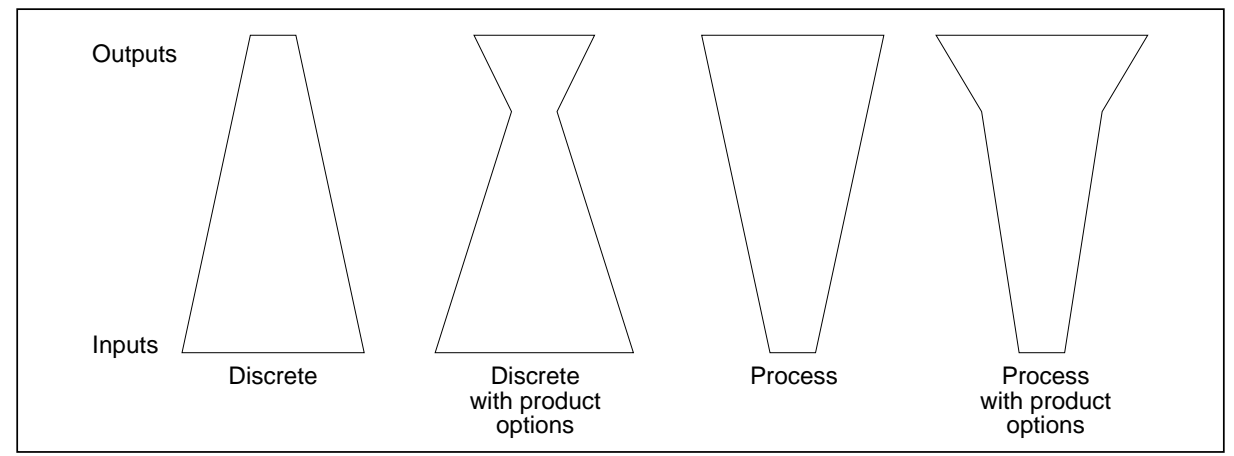

Figure 1.

Process and Discrete Manufacturing; Conceptual Differences 
IJOPM

14,12

50

and because it can cause the shop floor control system to expect a negative receipt of the output into stores. The by-product BOM connects processes as well as components and every process can have numerous outputs independent of the number of inputs. Duncan defines a task-item which is a process. Every task-item (process) gets input from processed items (the components) or from other task-items. The output of a task-item is one or more processed items (components). The features of the by-product BOM are that the bill can handle multiple outputs and multiple inputs, and that many levels of the bill can betied together through the process task-items.

A common problem is the unit of measure ("quantity per"). The manufacturing BOM shows component quantities per batch of parent (e.g. litres) and the product BOM, as used for forecasting etc., shows component quantities per unit of parent (e.g. bottles)[16]. This problem can be solved by finding a common denominator[1]. Furthermore, the per unit BOM needs to accommodate many decimal places because of the unit of measure relationship in the BOM between stocking units. For example, the active ingredient of a pain-killing tablet is stock in kilograms, but the standard tablet contains $0.00325 \mathrm{~kg}$ (325 milligrams)[11]. Rice and Norback[12] use matrix data structures to solve the unit of measure problem. They build matrices of the production scheduleand the product structure, with which they can allocate the

\begin{tabular}{|c|c|c|}
\hline Characteristic & Literature & Example of industry \\
\hline Variable yield & $\begin{array}{l}\text { Sepheri et al.[7] } \\
\text { Haglund et al.[8] } \\
\text { Burt and Kraemer[9] } \\
\text { Burt[10] } \\
\text { May[11] }\end{array}$ & Chemical industry \\
\hline Variable quality & $\begin{array}{l}\text { Taylor et al.[4] } \\
\text { Rice and Norback[12] } \\
\text { Kochalka[1] }\end{array}$ & Oil forest products \\
\hline Variable quantity/availability & Cokins[14] & Coffee, agricultural industry \\
\hline Variable recipe & $\begin{array}{l}\text { Taylor et al..[4] } \\
\text { Rutten[13] }\end{array}$ & Oil (animal) food industry, paper \\
\hline Divergent flow & Fransoo[15] & Glass \\
\hline Price of raw materials & Taylor et al.[4] & A gricultural \\
\hline Divergent BOM/by-products & $\begin{array}{l}\text { Cokins[14] } \\
\text { Rice and Norback[12] } \\
\text { May[11] } \\
\text { Duncan[2] }\end{array}$ & Beef cutting, forestry \\
\hline $\begin{array}{l}\text { Unit of measure/batch } \\
\text { problem }\end{array}$ & $\begin{array}{l}\text { A ppoo[16] } \\
\text { Kochalka[1] } \\
\text { May[11] } \\
\text { Rice and Norback[12] } \\
\text { Nelson[3] }\end{array}$ & Fine chemicals, drugs \\
\hline
\end{tabular}

Table I.

Characteristics Mentioned in the Literature 
costs of capacities and materials to the products. A nother effect of batch production in process industries, is that usually the total batch must be scrapped when the quality is poor. In discrete batch manufacturing a portion of the total batch might be rejected, but it is unlikely that the entire batch would be rejected[3].

The characteristics found in the literature, are summarized in Table I. A s mentioned above, a lot of these typical characteristics have been tackled in terms of data registration. However, in order to address the control problem, process industries will be characterized from a different point of view. This will be clarified in the development of a typology in the next section.

\section{Typology}

Samuel Taylor and his research group published an innovative series of articles in the first half of the 1980s on production control in process industries. In one of their first articles[4], they discuss a typology of industries in general into which they fit all kinds of process industries. The two dimensions they use are: degree of product differentiation and material flow complexity. The degree of product differentiation refers to the marketing environment of the business; the material flow complexity refers to the way the production process is organized. Taylor already notes that some fabrication (i.e. discrete) industries tend towards the flow shop/commodity type, while some process industry groups (e.g. speciality chemicals) are in the centre of the matrix. So both process and discrete manufacturers are spread over the matrix.

A s appears from Figure 2, which depicts this typology, these two axes are in fact one: the more an industry appears to be a job shop, the more its products are customer specific. Therefore, we propose to only use one axis with two extremes: job shop/custom specific and flow shop/commodity. Only process industries will be included in this typology. Industries producing discrete products are excluded. Products are not discrete if individual items are

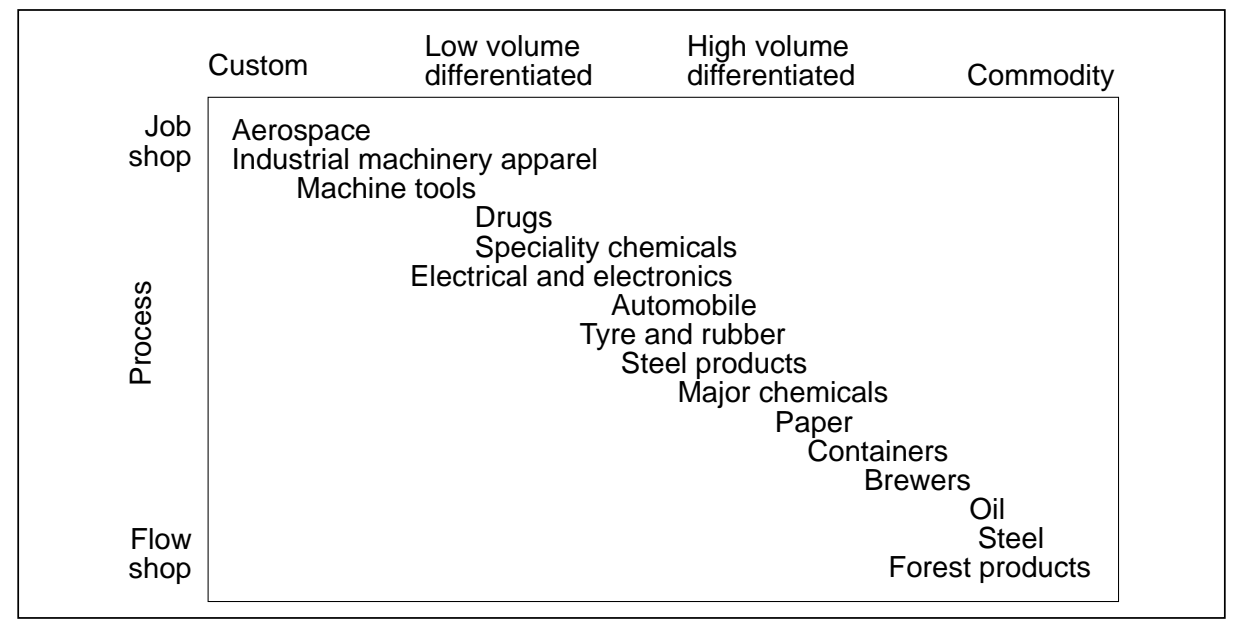

Figure 2.

Taylor's Typology 
IJOPM

14,12

52

indistinguishable from each other (like oil, chemicals) or if the products are simpleand produced in very large quantities such that it does not make sense to distinguish them individually (like glass bottles, aluminum cans). This characterization refers to a single-phase process. In case of a multi-phase production system, it is obvious that this refers to the most important step in the production process (which creates the majority of the added value). Our typology is presented in Figure 3.

The A PICS process industry definition already discriminates these two types of process industries, stating "... Processes may be either continuous or batch...". We use the names and definitions provided by the A PICS Process Industry T hesaurus[5]. As mentioned above, batch/mix is defined as:

A process business which primarily schedules short production runs of products.

Process/flow is defined as:

A manufacturer who produces with minimal interruptions in any one production run or between production runs of products which exhibit process characteristics such as liquids, fibres, powders, gases.

The discriminating characteristics of each type are presented in Table II.

In process/flow businesses, the lead time is mainly determined by the cycle time, i.e. the time betw een two consecutive runs of the same product. The actual processing time per unit is very small, but due to the high change-over times and the high production speed, the production orders are large. The number of different products is not only limited, but there is also relatively little variety between the products. Little variety, low product complexity and the small number of production steps cause all products to have the same routing. Since the total market demand for the relatively small number of products is high, investments in specialized single-purpose equipment are economically justifiable. The use of singlepurpose equipment simplifies the determination of available capacity: usually the installations are used continuously (round-the clock production). The added value in general is quite low. Since the production speed is very high, the material costs usually account for 60-70 per cent of the cost price. The characteristics of process/flow businesses are summarized in the left-hand column of Tablell.

In batch/mix businesses, on the other hand, the number of process steps is larger and the level of product complexity is higher[17]. In fine chemicals

Figure 3.

One-dimensional Typology for Process Industries

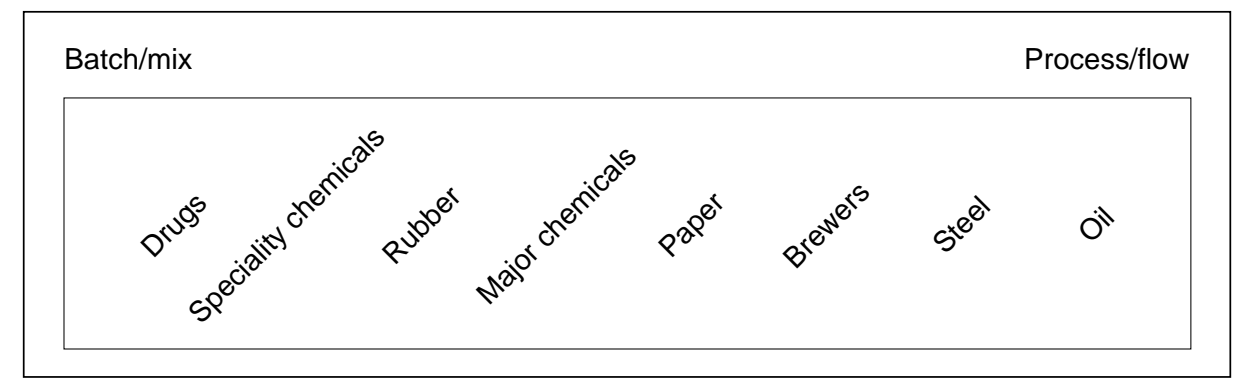




\begin{tabular}{|ll|}
\hline $\begin{array}{l}\text { Process/flow businesses are } \\
\text { characterized by }\end{array}$ & $\begin{array}{l}\text { Batch/mix businesses are } \\
\text { characterized by }\end{array}$ \\
\hline $\begin{array}{l}\text { High production speed, short } \\
\text { throughput time }\end{array}$ & $\begin{array}{l}\text { L Long lead time, much work in } \\
\text { process }\end{array}$ \\
- Clear determination of capacity, & - Capacity is not well-defined (different \\
one routing for all products, & configurations, complex routings) \\
no volume flexibility & - More complex products \\
- Low product complexity & - High added value \\
- Low added value & - Less impact of changeover times \\
- Strong impact of changeover times & - Large number of production/ \\
- Small number of production steps & process steps \\
- Limited number of products & - Large number of products \\
\hline
\end{tabular}

Production Control Situations

production, for instance, sometimes more than ten different production steps can be distinguished. Since the large variety of products requires the use of the same - general type - of equipment, routings are much more complex. In some cases, even the process configurations are adapted: series of installations are rebuilt and reconnected to make a certain type of process possible (retrofitting). Consequently, lead times are longer and the work in process is higher; intermediate storage is more common than in process/flow businesses. A dditionally, it is very difficult to make a good estimate of the available capacity. Lot sizes are predominantly determined by the technical batch size requirement instead of the changeover times. As a result of the increased product complexity compared to process/flow businesses, the share of raw materials in the cost price is lower than in process/flow businesses and the added value is higher. The characteristics of batch/mix businesses are summarized in the right-hand column of Table ll.

The production control structure to be used in process industries is dependent upon the position of the business on the axis in Figure 3. In the next section, we will discuss the typical production control aspects for each of the extremes on the axis.

\section{Production and Inventory Control}

In the planning, scheduling and control literature, an explicit distinction between the process/flow environments and the batch/mix production systems has not been made. The concepts and approaches offered, however, each focus on one of the two extremes. In this section, we will classify the planning, scheduling and control literature which is relevant to process industries. We will first discuss the process/flow businesses, and then the batch/mix industries. 
IJOPM

14,12

54
Production and Inventory Control in Process/Flow Businesses

The research applicable to process/flow industries, may be classified into the following categories:

- general production control concepts and structures;

- scheduling approaches and heuristics;

- integrated production control and scheduling approaches.

T he A PICS process industry work groups have focused on the development of a general production control concept. A production control concept is the description of and relations between all decision functions regarding the management of materials flow and capacity resources. The A PICS process industries "planning system framew ork" is presented in Bolander et al.[18]. T he framework strongly resembles the MRP II framework with a more dominant position for the resource requirements planning and production scheduling functions. The framework does not present an integrated approach as far as techniques go, but it is assumed that each decision function can be equipped with readily available or newly developed techniques. The interaction betw een the different techniques is established using a detailed flow of information between the various decision functions.

Scheduling approaches have been developed around the single machine multiproduct lot-sizing and scheduling problem. A vast body of literature has paid attention to this problem, especially the deterministic problem (E conomic Lot Scheduling Problem) (ELSP). A n excellent overview of the ELSP is presented by Elmaghraby[19]. Later, the problem with stochastic demand has been analysed. The first researchers to study this problem in detail were Leachman and Gascon[20]. In an original paper they investigate the applicability of deterministic models in stochastic situations, and present a heuristic to deal better with the uncertainty.

The well-known Massachusetts Institute of Technology hierarchical production planning systems, integrating a control concept and detailed scheduling decisions[21], have been applied in process industries and singlestage systems as well[22]. Hax and M eal use the aggregation of products to families, and from families to types, to make more aggregate decisions on a longer-term horizon. In this way, the planning and scheduling is more detailed if the horizon is shorter, and more aggregate if the horizon is longer. Since their approach is general and not restricted to process industries, they do not discuss issues like high change-over times, as a dominant control parameter.

This dominance of the long cycle times as an important parameter is the principle of the conceptual aggregation model developed at Eindhoven University of Technology [23]. This approach has been worked out in more detail by Fransoo[24,25]. In this model, the cycle times are not only determined by considering cost, but also by considering capacity consequences. This leads to a two-tiered model, in which at the higher level the cycle times are determined, and at the lower level the actual on-line scheduling takes place. 
Production and Inventory Control in Batch/M ix Businesses

The planning scheduling and control literature in the batch/mix area of research is differently oriented. This is mainly caused by the fact that this research has been developed in the chemical engineering area, while the process/flow production control literature has developed in the operations research and management science area.

Since chemical engineers do not limit themselves to the operational planning, scheduling and control of the system, but also include process design and process control, these aspects are sometimes integrated into the planning and scheduling issues.

We can classify the literature according to the decision functions that are addressed:

(1) design of the production system (grass roots);

(2) redesign of the production system (retrofitting);

(3) planning/scheduling of the production system (off-line);

(4) control of the production system (on-line scheduling);

(5) process control.

In this article, we focus on the third and fourth decision functions mentioned above. A $n$ excellent overview of the state of the art in grass roots design and retrofitting can be found in Reklaitis[26]. In the batch/mix literature, a clear distinction is made between off-line scheduling and online scheduling[27]. Offline scheduling is the creation of a predetermined schedule, assuming deterministic demand and production. Online scheduling is the continuous adaptation of the off-line schedule, reacting to changes in demand and production. This distinction is similar to the distinction in deterministic and stochastic scheduling rules in the single-machine multi-product problems discussed above. However, the emphasis placed on the processing of information is much higher in the batch/mix literature[26,28]. This is probably due to the higher complexity as compared to process/flow businesses.

The exchange of information between different control levels, including process control, is illustrated in Cott and M acchietto[29]. A Iso the integration of off-line scheduling and process design is discussed in the literature. Usually, in the design process, some assumptions about demand are made, and simultaneously to the design, an off-line schedule is created[30]. Sometimes, the possibility to physically partially reorganize the plant equipment still exists. One could think of combining different reactors by pipes in various ways. If this limited equipment design is combined to a scheduling problem, this is called a retrofitting problem[31].

From the above description, it is clear that in the batch/mix problem, there are more degrees of freedom, and also that there are more interrelationships between production units and material flows. Both production flow complexity and material complexity are high. The high number of production steps, the presence of intermediate storage, and the divergent materials flow enables 
IJOPM

14,12

56 postponing the scheduling decision until the latest possible moment, i.e. when a decision needs to be taken in which unit a specific batch is going to be produced. This approach is a flexible scheduling approach, and should be designed in such a way that each decision leaves maximum flexibility to the following scheduling decisions. This seems a promising avenue for further research and deserves increased attention in Production and Operations M anagement (POM) research.

\section{Conclusions}

The objective of this article was to present a reference model or typology for research in production planning and scheduling in process industries. The typology was supported by classifying illustratively a number of papers according to this typology. It was concluded that a clear distinction needs to be made between the research in process/flow and in batch/mix businesses. In process/flow industries, the concept of Leachman and Gascon[20] has proven to be of considerable value for uncapacitated problems. The concept of Fransoo[25] could be used as a basic model for capacitated situations. These concepts can be worked out in detail for company-specific situations. Especially the distinction between make-to-stock and maketo-order companies may lead to different varieties of the respective concepts. A concept for process/flow businesses in make-to-order situations using the same basic ideas as Fransoo[25] can be found in Bertrand, et al.[23]. In batch/mix industries, detailed scheduling and design procedures have been developed by chemical engineers. A more general framework for this situation, involving flexible scheduling procedures within a decision framework, is however lacking and should receive increased research attention. The excellent work done by the chemical engineering research community should however be incorporated in this model.

\section{References}

1. Kochalka, T.S., "M RP in a Process Industry - Why Wait?", Production and Inventory M anagement Journal, Vol. 19 No. 4, 1978, pp. 17-20.

2. Duncan, R.M., "T he By-product Bill of Material", A PICS Conference Proceedings, 1983, pp. 288-92.

3. Nelson, N.S., "MRP and Inventory and Production Control in Process Industries", Production and Inventory M anagement Journal, Vol. 24 No. 4, 1983, pp. 15-22.

4. Taylor, S.G., Sewart, S.M . and Bolander, S.F., "W hy the Process Industries A re Different", Production and Inventory M anagement Journal, Vol. 22 No. 4, 1981, pp. 9-24.

5. Connor, S.J., Process Industry T hesaurus, A merican Production and Inventory Control Society, Falls Church, VA, 1986.

6. Wallace, T.F. (Ed.), A PICS Dictionary, 5th ed., A merican Production and Inventory Control Society, Falls Church, VA, 1984.

7. Sepehri, M., Silver, E.A . and New, C., "A Heuristic for Multiple Lot Sizing for an Order under Variable Y ield", IIE Transactions, Vol. 16 No. 1, 1986, pp. 63-9.

8. Haglund, E .A., "Primary M etals - We're Different", Production and Inventory M anagement Journal, Vol. 22 No. 3, 1981, pp. 21-6.

9. Burt, J. and Kraemer, B., "Integrating Material and Product Control Systems into a T ightly Regulated Processing Environment", A PICS Conference Proceedings, 1979, pp. 32-4. 
10. Burt, J., "Master Production Scheduling Considerations for Process Industries", A PICS Conference Proceedings, 1980, pp. 417-18.

11. May, N.P., "T he Functions Needed for Process-oriented Systems", A PICS Conference Proceedings, 1984, pp. 29-32.

12. Rice, J.W. and Norback, J.P., "Process Industries Production Planning Using Matrix Data Structures", Production and Inventory M anagement Journal, Vol. 28 No. 2, 1987, pp. 15-23.

13. Rutten, W.G.M.M., "Hierarchical Mathematical Programming for Operational Planning in a Process Industry", European Journal of Operational Research, Vol. 64 No. 3, 1993, pp. 363-9.

14. Cokins, G.M., "Control Systems for Process Industries", Manufacturing Systems, Vol. 6 No. 5, 1988, pp. 79-83.

15. Fransoo, J.C., Process Industries Logistics Characteristics, research report TUE/BDK/K BS/89-01, Eindhoven University of Technology, 1989.

16. A ppoo, P.M., "A Practical M ethod of Implementing the Batch BOM in the Process Industries", Production and Inventory Management Journal, Vol. 28 No. 2, 1987, pp. 79-84.

17. Rippin, D.W.T., "Batch Process Planning”, Chemical Engineering, Vol. 98 N o. 5, 1991, pp. 100-7.

18. Bolander, S.F., Heard, R.C., Seward, S.M . and T aylor, S.G., M anufacturing Planning and Control in Process Industries, A merican Production and Inventory Control Society, Falls Church, VA, 1981.

19. Elmaghraby, S.E., "T he Economic Lot Scheduling Problem (ELSP): Review and Extensions", M anagement Science, Vol. 24 No. 6, 1978, pp. 587-98.

20. Leachman, R.C. and Gascon, A., "A Heuristic Scheduling Policy for Multi-item, Singlemachine Production Systems with T ime-varying, Stochastic Demands", M anagement Science, Vol. 34 No. 3, 1988, pp. 377-90.

21. Bitran, G.R. and Hax, A.C, "On the Design of Hierarchical Production Planning Systems", Decision Sciences, Vol. 8 No. 1, 1977, pp. 28-55.

22. Bitran, G.R., Haas, E.A . and Hax, A.C., "Hierarchical Production Planning: A Single Stage System", Operations Research, Vol. 29 N 0. 4, 1981, pp. 717-43.

23. Bertrand, J.W.M., Wortmann, J.C. and Wijngaard, J., Production Control: A Structural and Design Oriented A pproach, Elsevier, A msterdam, 1990.

24. Fransoo, J.C., "Demand M anagement and Production Control in Process Industries", International Journal of Operations \& Production Management, Vol. 12 No. 7/8, 1992, pp. 187-96.

25. Fransoo, J.C., Production Control and Demand M anagement in Capacitated Flow Process Industries, PhD Thesis, Eindhoven University of Technology, 1993.

26. Reklaitis, G.V., "Progress and Issues in Computer-aided Batch Process Design", in Siirola, J.J., Grossman, I.E. and Stephanopoulos, G. (E ds), Foundations of Computer-aided Process Design, Elsevier, A msterdam, 1990, pp. 241-75.

27. Cott, B.J. and Machietto, S., "A General Completion T ime Determination A lgorithm Using On-line Schedule M odification", Computers and Chemical Engineering, Vol. 13 Nos. 1/2, 1989, pp. 105-13.

28. Jänicke, W., "Computergestützte A pparatebel egung für M ehrzweckanlagen", ChemieIngenieur-T echnik, Vol. 64 No. 4, 1992, pp. 368-70 (in German).

29. Cott, B.J. and M achietto, S., "A n Integrated A pproach to Computer-aided Operation of Batch Chemical Plants", Computers and Chemical Engineering, Vol. 13 Nos. 11/12, 1989, pp. 1263-71.

30. Mauderli, A and Rippin, D.W.T., "Production Planning and Scheduling for Multi-purpose Batch Chemical Plants", Computers and Chemical Engineering, Vol. 3, 1979, pp. 199-206.

31. Espuna, A and Puigjaner, L., "On the Solution of the Retrofitting Problem for Multiproduct Batch/Semicontinuous Chemical Plants", Computers and Chemical Engineering, Vol. 13 Nos. 4/5, 1989, pp. 483-90. 